\title{
Avocado and Cardiovascular Health
}

\author{
Camila Weschenfelder ${ }^{1}$, Júlia Lorenzon dos Santos ${ }^{1}$, Priscilla Azambuja Lopes de Souza1, \\ Viviane Paiva de Campos ${ }^{1}$, Aline Marcadenti ${ }^{12^{*}}$ \\ ${ }^{1}$ Postgraduate Studies Program in Cardiology, Instituto de Cardiologia/Fundação Universitária de Cardiologia \\ do Rio Grande do Sul (IC/FUC), Porto Alegre, Brazil \\ ${ }^{2}$ Department of Nutrition, Federal University of Health Sciences of Porto Alegre (UFCSPA), Porto Alegre, Brazil \\ Email: ${ }^{*}$ marcadenti@yahoo.com.br
}

Received 30 June 2015; accepted 25 July 2015; published 29 July 2015

Copyright (C) 2015 by authors and Scientific Research Publishing Inc.

This work is licensed under the Creative Commons Attribution International License (CC BY).

http://creativecommons.org/licenses/by/4.0/

(c) () Open Access

\begin{abstract}
Avocado is a fruit which had a caloric density of $1.7 \mathrm{kcal}$ per gram and a half unit $(\sim 70 \mathrm{~g})$ is composed by $114 \mathrm{kcal}, 4.6 \mathrm{~g}$ of fibers, $345 \mathrm{mg}$ of potassium, $19.5 \mathrm{mg}$ of magnesium, $1.3 \mathrm{mg}$ of vitamin $\mathrm{E}$ and $57 \mathrm{mg}$ of phytosterols. Approximately $\mathbf{7 5 \%}$ of fiber's avocado contents are considered insoluble and $25 \%$ are soluble. The avocado contains lipids that consist of $\mathbf{7 1 \%}$ from monounsaturated fatty acids (MUFA), 13\% from polyunsaturated (PUFA) and 16\% from saturated fatty acids (SFA). Recent researches have shown that avocado may improve hypercholesterolemia and may be useful in the treatment of hypertension and type 2 diabetes mellitus (T2DM). This way, avocado plays an important role in the cardiovascular health. This review summarizes the potential benefits of avocado consumption in the prevention of cardiovascular risk factors and metabolic diseases.
\end{abstract}

\section{Keywords}

Persea, Diabetes Mellitus, Type 2, Dyslipidemias, Nutritional Status, Blood Pressure

\section{Introduction}

The tree of the avocado is originally from Mexico and Central America, and belongs to the Lauraceae family, genus Perseal [1]-[3]. This genus is divided into two subgenuses: Persea and Eriodaphne [3]. However, there are two important species in horticulture: Persea americana Mill and Persea drymifolia cham.; this last comprising Mexican race avocados, which currently is considered as the botanical variety of Persea Americana [3] [4].

The avocado is a fruit which had a caloric density of $1.7 \mathrm{kcal}$ per gram and a half unit $(\sim 70 \mathrm{~g})$ is composed by $114 \mathrm{kcal}, 4.6 \mathrm{~g}$ of fibers, $345 \mathrm{mg}$ of potassium, $19.5 \mathrm{mg}$ of magnesium, $1.3 \mathrm{mg}$ of vitamin $\mathrm{E}$ and $57 \mathrm{mg}$ of phy-

"Corresponding author.

How to cite this paper: Weschenfelder, C., dos Santos, J.L., de Souza, P.A.L., de Campos, V.P. and Marcadenti, A. (2015) Avocado and Cardiovascular Health. Open Journal of Endocrine and Metabolic Diseases, 5, 77-83. 
tosterols (Table 1) [5]. Approximately 75\% of fiber's avocado contents are considered insoluble and 25\% are soluble [6]. The avocado contains lipids that consist of $71 \%$ from monounsaturated fatty acids (MUFA), 13\% from polyunsaturated (PUFA) and 16\% from saturated fatty acids (SFA) [7]. Its high MUFA content in a waterbased matrix appears to enhance the bioavailability of nutrients and phytochemical compounds of the avocado [8].

The avocado consumption has been related to benefits on some cardiovascular risk factors [5] [9], as well as to the improvement of the dietary quality and nutrient intake by increasing the consumption of MUFA, dietary fiber, magnesium, potassium, vitamins $\mathrm{E}$ and $\mathrm{K}$ [10]. Recent researches have shown that avocado can improve hypercholesterolemia and be useful in the treatment of hypertension (HTN) and type 2 diabetes mellitus (T2DM). This way, avocado can play an important role in the cardiovascular health.

This review aims to summarize the potential benefits of avocado consumption in the prevention of cardiovascular risk factors and metabolic diseases.

\subsection{Avocado and Type 2 Diabetes Mellitus}

The World Health Organization (WHO) have update the prevalence of T2DM in the United States (estimated about 30.3 million people by 2025) and worldwide, which is estimated around 380 million people diagnosed until the same year [11]. T2DM is associated with obesity, unhealthy diet, sedentary lifestyle and aging population

Table 1. Nutritional composition of the Hass avocado (Persea americana) ${ }^{5}$.

\begin{tabular}{|c|c|}
\hline Nutrient/Phytochemical & Value per $100 \mathrm{~g}$ \\
\hline \multicolumn{2}{|l|}{ Proximates } \\
\hline Water (g) & 72.3 \\
\hline Energy (Kcal) & 167 \\
\hline Protein (g) & 1.96 \\
\hline Fat (g) & 15.4 \\
\hline Carbohydrate (g) & 8.64 \\
\hline Fiber, total dietary (g) & 6.8 \\
\hline Sugars, total (g) & 0.3 \\
\hline \multicolumn{2}{|l|}{ Minerals } \\
\hline Magnesium (mg) & 29 \\
\hline Phosphorus (mg) & 54 \\
\hline Potassium (mg) & 507 \\
\hline Sodium (mg) & 8 \\
\hline Zinc (mg) & 0.68 \\
\hline Selenium (ug) & 0.4 \\
\hline \multicolumn{2}{|l|}{ Vitamins/Phytochemicals } \\
\hline Vitamin C (mg) & 8.8 \\
\hline Folate, food $(\mu \mathrm{g})$ & 89 \\
\hline Lutein + zeaxanthin $(\mu \mathrm{g})$ & 271 \\
\hline Vitamin E (alpha-tocopherol) (mg) & 1.97 \\
\hline \multicolumn{2}{|l|}{ Lipids } \\
\hline Fatty acids, total saturated (g) & 2.13 \\
\hline Fatty acids, total monounsaturated (g) & 9.8 \\
\hline Fatty acids, total polyunsaturated (g) & 1.82 \\
\hline Cholesterol (mg) & 0 \\
\hline
\end{tabular}

Adapted from Dreher ML et al. ${ }^{5}$. 
[12]. Patients with fasting plasma glucose $\geq 126 \mathrm{mg} / \mathrm{dL}$, oral glucose tolerance test (75 g glucose load) $\geq 200$ $\mathrm{mg} / \mathrm{dL}$ or glycated hemoglobin $\geq 6.5 \%$ [13] are diagnosed with T2DM. Patients with diabetes are at high risk for microvascular (e.g., nephropathy, retinopathy and neuropathy) and macrovascular complications (e.g., peripheral vascular disease, stroke and cardiovascular disease) [12].

Avocado has low sugar content (0.2 $\mathrm{g}$ in a half unity). D-mannoheptulose is the main kind of sugar found in the fruit but is seems do not have nutritional properties, appearing to be one more phytochemical component of the avocado [9]. The aqueous extract from the avocad's seeds has hypoglycemic agents, which act protecting against toxicity and oxidative stress [14]-[16]. In rats, phenolic extracts of avocado (from leaves and fruits) inhibited the activity of enzymes related to the development of T2DM ( $\alpha$-amilase and $\alpha$-glucosidase), as well as the malondialdehyde production (MDA), a marker of oxidative stress and responsible for increasing the lipid peroxidation [17]. The hypoglycemic effect of the avocado was also related to its ability to stimulate the remaining pancreatic $\beta$-cells in animal models, making them able to secrete more insulin [18].

Diets rich in MUFA are considered alternatives for the dietary treatment of T2DM [19] and since avocado have a substantial amount of MUFA it could be used as an option for glycemic control in diabetic patients. However, few studies had evaluated the use of avocado in individuals with T2DM. Among overweight and moderately obese individuals, adding half avocado $(70 \mathrm{~g})$ in the lunch increased the satiety in a period of 3 to 5 subsequent hours, followed by a reduction of the insulin secretion in a 3-hour postprandial period [20]. Patients with hypercholesterolemia and T2DM supplemented with 300g/day of avocado for 7 days had their total cholesterol (TC) and LDL-cholesterol decreased by $17 \%$ and 22\% respectively, and their triglycerides (TG) levels reduced by $22 \%$; there was also a slightly increase in HDL-cholesterol when compared to the control group (isocaloric diet, $50 \%$ of total calories from fats and without avocado) [21].

The avocado paste can be obtained by the fruit oil and its effects were evaluated in rats, who consumed a hypercholesterolemic diet added of glucose solution and also the paste of avocado. Authors concluded that the animals had lower levels of blood sugar, lower values of the Homeostasis Model Assessment-Insulin Resistance Index (HOMA-IR Index) and less accumulation of fat in their liver. In this study, the improvement of the HOMA-IR Index and of the hepatic steatosis was attributed to the phytochemicals components and dietary fibers of the avocado [22].

\subsection{Avocado and Dyslipidemia}

Dyslipidemia is defined as lipid metabolic changes resulting from disturbances in any phase of the lipid metabolism, which impact on serum lipoproteins levels. It is an important cardiovascular risk factor: about a third of ischemic heart diseases are attributable to increased levels of TC. Globally, higher levels of cholesterol are responsible for 2.6 million deaths annually, and the treatment of dyslipidemia may reduce the cardiovascular risk by $30 \%$ over a period of 5 years [23] [24].

Nutritional therapy and changes in lifestyle are part of the non-pharmacological treatment for dyslipidemia. The American Heart Association/American College of Cardiology (AHA/ACC) recommends a healthy eating pattern, with $5 \%$ to $6 \%$ of total daily calories from SFA to reduce the levels of LDL-cholesterol [25]; SFA should be replaced by MUFA and PUFA intake [26] [27]. MUFA have benefic effect on hypercholesterolemia without increasing the lipid oxidation, in contrast with excessive intake of PUFA; MUFA ingestion also does not reduce serum HDL-cholesterol levels [28]. Recently, the PREDIMED study (Prevención con Dieta Mediterránea) showed that the Mediterranean diet supplemented with foods rich in MUFA (olive oil and nuts) reduced the incidence of major cardiovascular events by $30 \%$ after a follow-up of 4.8 years, in subjects at high risk for cardiovascular disease [29].

The lipid-lowering effect of avocado (also rich in MUFA) occurs mainly due its phytosterol $\beta$-sitosterol [30]. Among 17,567 participants of the National Health and Nutrition Examination Survey (NHANES: 2001-2008) who had their avocado intake evaluated, the average daily intake was about a half of unit (70.1 $\pm 5.4 \mathrm{~g} / \mathrm{day})$, and the avocado consumers had higher levels of HDL-cholesterol when compared to those who did not consume [10].

The first clinical trial evaluating the influence of the avocado on serum TC was carried out by C. Grant Wilson in 1960 [31]. At that time, 16 men aged between 27 and 71 years (with and without hypercholesterolemia) were advised to consume 0.5 to 1.5 units of avocado a day. After 4 weeks, 8 participants had their TC reduced by $8.7 \%$ to $42.8 \%$, without changing other lipid parameters. Subsequently, Carranza et al. [32] evaluated the effect of two diets in 16 individuals with dyslipidemia: 1 ) a diet rich in avocado (75\% of total fat); or 2) a low sa- 
turated fat/low dietary cholesterol diet. After 4 weeks, results showed that individuals allocated to the avocado diet had lower levels of TC and LDL-cholesterol and increased serum HDL-cholesterol.

Avocado may modify the structure of the HDL lipoprotein by increasing paraoxonase1 (PON1) enzyme activity. The cardioprotector effect of HDL-cholesterol is in part due of PON1 activity, which is responsible for the hydrolysis of lipid hydroperoxides (products of the lipid oxidation) [33] [34]. About LDL-cholesterol particles, a randomized controlled trial was conducted among 45 overweight/obese participants submitted to a 2-week run-in diet (Average American Diet, AAD) and later allocated to three distinct diets: 1) LF-low fat diet (24\% of daily total calories from fats); 2) MF-moderate fat diet (34\% of daily total calories from fats); or 3) AVavocado diet ( $140 \mathrm{~g}$ of Hass avocado a day $13 \mathrm{~g}$ of MUFA). The AV diet group showed higher reduction of LDL and non-HDL cholesterol when compared to the other diets, and had reduced values of total LDL-cholesterol particles (LDL-P $-80.1 \mathrm{nmol} / \mathrm{l}, \mathrm{p}=0.0001$ ), subclasses of LDL-cholesterol (LDL ${ }_{3+4}-4.1 \mathrm{mg} / \mathrm{dl}, \mathrm{p}=0.04$ ) and LDL/HDL ratio ( $-6.6 \%, \mathrm{p}<0.0001$ ). AV and MF diets reduced apolipoprotein B-100 (ApoB) levels and the relationship between ApoB/ApoA-I decreased in AV diet group, without weight changes [35].

\subsection{Avocado and Nutritional Status}

The pathophysiological processes linking obesity to atherosclerosis and cardiovascular disease clearly involve a chronic inflammatory state [36], which interact with other factors such as ectopic fat, insulin resistance and HTN. For weight management and prevention of cardiovascular disease, international dietary recommendations regarding MUFA ingestion vary from $12 \%$ to $25 \%$ of total daily calories [37].

Popularly, avocado is known by its high caloric value being "a fruit whose consumption should be contraindicated in diets for weight loss." In fact, few studies have evaluated the avocado in the weight loss setting.

Pieterse et al. conducted a clinical trial among 61 overweight/obese subjects, who were randomly assigned in two groups (an isocaloric diet with or without $200 \mathrm{~g}$ /day of avocado). After 6 weeks individuals in both groups reduced their weight, Body Mass Index (BMI) and body fat percentage, without significant differences according to group. In other study for weight maintenance, 131 subjects were allocated for three diets: 1) a moderate fat diet (34\% to $45 \%$ of total daily calories from fats, including $100 \mathrm{~g} /$ day of avocado); 2 ) a low fat diet (20\% to $30 \%$ of total daily calories from fats); or 3) a control diet (35\% of total calories from fats). After 6 months all groups showed significant increase body weight, without differences between them [38]. In general, avocado consumers had a higher daily consumption of fruits and vegetables, essential foods included in a healthy diet for reduction or maintenance of the body weight [39] [40].

\subsection{Avocado and Blood Pressure}

Hypertension is the leading cause of worldwide mortality and is responsible for approximately $40 \%$ of deaths from cardiovascular disease, chronicle kidney disease (CKD) and type 2 diabetes mellitus (T2DM) [41]. Beyond weight reduction, the adoption of a DASH diet is a part of the non-pharmacological treatment for higher levels of blood pressure (BP) (systolic and diastolic BP > 140/90 $\mathrm{mmHg}$ ) [42].

The high content of potassium and lutein in the avocado may improve the BP values by controlling oxidative stress and inflammation ${ }^{5}$. In addition, diets rich in MUFA may improve systolic and diastolic BP levels when compared to diets with low content of MUFA [43].

Experimental studies have evaluated the potential hypotensive effect attributed to the aqueous extract of the avocado leaves [44]-[46]. Ojewola et al. [44] showed that the vascular dilation in consequence to the aqueous extract intake was the responsible for an anti-hypertensive effect of the avocado in rats. Authors suggest that different phytochemical components in the avocado's extract caused this effect. In other study, the aqueous extract from avocado seeds used as treatment for HTN in rats reduced BP levels and also improved the lipid profile [47]. In humans, subjects with overweight and moderate obesity who received a restricted caloric diet supplemented with $200 \mathrm{~g}$ of avocado a day do not had their BP levels reduced after the intervention [38].

\section{Conclusions}

The consumption of avocado seems to be related to cardiometabolic health by preventing traditional risk factors such as dyslipidemia, glycemic control and hypertension (Table 2). Despite all beneficial effects of avocado, 
Table 2. Summary of clinical trials regarding avocado consumption and cardiovascular risk factors.

\begin{tabular}{|c|c|c|c|c|c|c|}
\hline Author & Year & $\begin{array}{l}\text { No. } \\
\text { Participants }\end{array}$ & $\begin{array}{l}\text { Trial } \\
\text { Design }\end{array}$ & $\begin{array}{l}\text { Consumption } \\
\text { /follow-up }\end{array}$ & Intervention & Outcome (s) \\
\hline $\begin{array}{l}\text { Grant } \\
\text { et al. }[31]\end{array}$ & 1960 & 16 & Crossover & $\begin{array}{c}\text { Daily, } \\
\text { 4 weeks/phase }\end{array}$ & Avocado addition of 0.5 - 1.5 units & $\downarrow$ total cholesterol \\
\hline $\begin{array}{l}\text { Colquhoun } \\
\text { et al. }[21]\end{array}$ & 1992 & 15 & Crossover & $\begin{array}{c}\text { Daily, } \\
1 \text { week/phase }\end{array}$ & $\begin{array}{l}\text { Diet rich in MUFAs supplemented with } \\
300 \mathrm{~g} \text { avocado vs. diet rich in } \\
\text { complex carbohydrates }\end{array}$ & $\begin{array}{l}\downarrow \text { total cholesterol, LDL } \\
\text { and triglycerides, } \uparrow \mathrm{HDL} \\
\text { concentration }\end{array}$ \\
\hline $\begin{array}{l}\text { Carranza } \\
\text { et al. }[32]\end{array}$ & 1995 & 16 & Crossover & $\begin{array}{c}\text { Daily, } \\
4 \text { week/phase }\end{array}$ & $\begin{array}{c}\text { Diet rich in avocados ( } 75 \% \text { of total fat), } \\
\text { vs. diet low in saturated fat }\end{array}$ & $\begin{array}{l}\downarrow \text { total cholesterol and } \\
\text { LDL, } \uparrow \text { increased HDL } \\
\quad \text { concentration }\end{array}$ \\
\hline $\begin{array}{l}\text { Pieterse } \\
\text { et al. [38] }\end{array}$ & 2005 & 61 & Parallel & $\begin{array}{l}\text { Daily, } \\
6 \text { weeks }\end{array}$ & $\begin{array}{l}\text { Hypocaloric diet with inclusion of } 200 \mathrm{~g} \\
\text { of avocado or hypocaloric diet }\end{array}$ & $\begin{array}{l}\text { No difference regarding } \\
\text { weight reduction and blood } \\
\text { pressure }\end{array}$ \\
\hline $\begin{array}{l}\text { Sloth } \\
\text { et al. [39] }\end{array}$ & 2009 & 131 & Parallel & $\begin{array}{l}\text { Daily, } \\
6 \text { months }\end{array}$ & $\begin{array}{c}\text { Moderate fat diet with } 100 \mathrm{~g} \text { avocado or } \\
\text { low-fat diet or control diet }\end{array}$ & $\begin{array}{l}\text { No difference regarding } \\
\text { weight reduction }\end{array}$ \\
\hline $\begin{array}{l}\text { Wien } \\
\text { et al. [20] }\end{array}$ & 2013 & 26 & Crossover & $\begin{array}{l}1 \text { meal, } \\
\text { postmeal } \\
\text { measurement }\end{array}$ & Adding avocado 68g at lunch & $\begin{array}{c}\uparrow \text { satiety and } \downarrow \text { of fasting } \\
\text { insulin in postprandial } \\
\text { period of } 3 \mathrm{~h}\end{array}$ \\
\hline $\begin{array}{l}\text { Wang } \\
\text { et al. [35] }\end{array}$ & 2015 & 45 & Crossover & $\begin{array}{c}\text { Daily, } \\
5 \text { weeks/phase }\end{array}$ & $\begin{array}{l}\text { Low-fat diet, moderate fat diet or } \\
\text { moderate fat diet with addition } \\
\text { of } 136 \mathrm{~g} \text { of avocado per day }\end{array}$ & $\begin{array}{l}\downarrow \text { LDL and weight } \\
\text { maintenance }\end{array}$ \\
\hline
\end{tabular}

many studies were made in animal models and there results should be interpreted with caution. It is suggested that further studies must be designed among humans, in order to evaluate and to confirm the benefits of avocado.

\section{References}

[1] Montenegro, H.W.S. (1951) The Culture of Avocado. Melhoramentos, São Paulo, 11:102.

[2] Maranca, G. (1980) Commercial Fruit Growing: Mango and Avocado. Nobel, São Paulo, 81-133.

[3] Koller, O.C. (1992) Abacaticultura. UFRGS, Porto Alegre, 138.

[4] Canto, W.L., Santos L.C. and Travaglini, M.M.E. (1978) Avocado: The Crop to Processing and Marketing. Série frutas tropicais-1. ITAL, Campinas, 212.

[5] Dreher, M.L. and Davenport, A.J. (2013) Hass Avocado Composition and Potential Health Effects. Critical Reviews in Food Science and Nutrition, 53, 738-750. http://dx.doi.org/10.1080/10408398.2011.556759

[6] Naveh, E., Werman, M.J., Sabo, E. and Neeman, I. (2002) Defatted Avocado Pulp Reduces Body Weight and Total Hepatic Fat But Increases Plasma Cholesterol in Male Rats Fed Diets with Cholesterol. The Journal of Nutrition, 132, 2015-2018.

[7] USDA (U.S. Department of Agriculture) (2011) Avocado, Almond, Pistachio and Walnut Composition. Nutrient Data Laboratory. USDA National Nutrient Database for Standard Reference, Release 24. U.S. Department of Agriculture. Washington, DC.

[8] Unlu, N., Bohn, T., Clinton, S.K. and Schwartz, S.J. (2005) Carotenoid Absorption from Salad and Salsa by Humans Is Enhanced by the Addition of Avocado or Avocado Oil. The Journal of Nutrition, 135, 431-436.

[9] Wang, L., Bordi, P.L., Fleming, J.A., Hill, A.M. and Kris-Etherton, P.M. (2015) Effect of a Moderate Fat Diet with and without Avocados on Lipoprotein Particle Number, Size and Subclasses in Overweight and Obese Adults: A Randomized, Controlled Trial. Journal of the American Heart Association, 4, e001355. http://dx.doi.org/10.1161/jaha.114.001355

[10] Fulgoni 3rd, V.L., Dreher, M. and Davenport, A.J. (2013) Avocado Consumption Is Associated with Better Diet Quality and Nutrient Intake, and Lower Metabolic Syndrome Risk in US Adults: Results from the National Health and Nutrition Examination Survey (NHANES) 2001-2008. The Journal of Nutrition, 12, 1. http://dx.doi.org/10.1186/1475-2891-12-1

[11] Nicholson, G. and Hall, G.M. (2011) Diabetes Mellitus: New Drugs for a New Epidemic. British Journal of Anaesthesia, 107, 65-73. http://dx.doi.org/10.1093/bja/aer120

[12] Tangvarasittichai, S. (2015) Oxidative Stress, Insulin Resistance, Dyslipidemia and Type 2 Diabetes Mellitus. World Journal of Diabetes, 6, 456-480. http://dx.doi.org/10.4239/wjd.v6.i3.456 
[13] American Diabetes Association (2014) Standards of Medical Care in Diabetes. Diabetes Care, 37, $14-80$.

[14] Alhassan, A.J., Sule, M.S., Atiku, M.K., Wudil, A.M., Abubakar, H. and Mohammed, S.A. (2012) Effects of Aqueous Avocado Pear (Persea americana) Seed Extract on Alloxan Induced Diabetes Rats. Greener Journal of Medical Sciences, 2, 5-11.

[15] N'guessan, K., Amoikon, K.E. and Soro, D. (2009) Effect of Aqueous Extract of Persea americana Seeds on the Glycemia of Diabetic Rabbits. European Journal of Scientific Research, 26, 376-385.

[16] Ezejiofor, A.N., Okorie, A. and Orisakwe, O.E. (2013) Hypoglycaemic and Tissue-Protective Effects of the Aqueous Extract of Persea americana Seeds on Alloxan-Induced Albino Rats. The Malaysian Journal of Medical Sciences, 20, 31-39.

[17] Oboh, G., Isaac, A.T., Akinyemi, A.J. and Ajani, R.A. (2014) Inhibition of Key Enzymes Linked to Type 2 Diabetes and Sodium Nitroprusside Induced Lipid Peroxidation in Rats’ Pancreas by Phenolic Extracts of Avocado Pear Leaves and Fruit. International Journal of Biomedical Sciences, 10, 208-216.

[18] Rao, U.S. and Adinew, B. (2011) Remnant B-Cell-Stimulative and Anti-Oxidative Effects of Persea americana Fruit Extract Studied in Rats Introduced into Streptozotocin-Induced Hyperglycaemic State. African Journal of Traditional, Complementary and Alternative Medicines, 8, 210-217. http://dx.doi.org/10.4314/ajtcam.v8i3.65277

[19] Ros, E. (2003) Dietary Cis-Monounsaturated Fatty Acids and Metabolic Control in Type 2 Diabetes. The American Journal of Clinical Nutrition, 78, 617-625.

[20] Wien, M., Haddad, E., Oda, K. and Sabaté, J. (2013) A Randomized $3 \times 3$ Crossover Study to Evaluate the Effect of Hass Avocado Intake on Post-Ingestive Satiety, Glucose and Insulin Levels, and Subsequent Energy Intake in Overweight Adults. Nutrition Journal, 12,155. http://dx.doi.org/10.1186/1475-2891-12-155

[21] Colquhoun, D.M., Moores, D., Somerset, S.M. and Humphries, J.A. (1992) Comparison of the Effects on Lipoproteins and Apolipoproteins of a Diet High in Monounsaturated Fatty Acids, Enriched with Avocado, and a High-Carbohydrate Diet. The American Journal of Clinical Nutrition, 56, 671-677.

[22] Pahua-Ramos, M.E., Garduño-Siciliano, L., Dorantes-Alvarez, L., Chamorro-Cevallos, G., Herrera-Martínez, J., Osorio-Esquivel, O., et al. (2014) Reduced-Calorie Avocado Paste Attenuates Metabolic Factors associated with a Hypercholesterolemic-High Fructose Diet in Rats. Plant Foods for Human Nutrition, 69, 18-24. http://dx.doi.org/10.1007/s11130-013-0395-4

[23] Mendis, S., Puska, P. and Norrving, B. (2011) Global Atlas on Cardiovascular Disease Prevention and Control. World Health Organization.

[24] World Health Organization (2009) Global Health Risks: Mortality and Burden of Disease Attributable to Selected Major Risks. World Health Organization.

[25] Eckel, R.H., Jakicic, J.M., Ard, J.D., de Jesus, J.M., Houston, M.N., Hubbard, V.S., et al. (2013) AHA/ACC Guideline on Life Style Management to Reduce Cardiovascular Risk: A Report of the American College of Cardiology/American Heart Association Task Force on Practice Guidelines. Circulation, 129, S76-S99. http://dx.doi.org/10.1161/01.cir.0000437740.48606.d1

[26] Xavier, H.T., Izar, M.C., Faria Neto, J.R., Assad, M.H., Rocha, V.Z., Sposito, A.C., et al. (2013) V Brazilian Guideline of Dyslipidemia and Prevention of Atherosclerosis. Arquivos Brasileiros de Cardiologia, 101, 1-20. http://dx.doi.org/10.5935/abc.2013S010

[27] Santos, R.D., Gagliardi, A.C.M., Xavier, H.T., Magnoni, C.D., Cassani, R. and Lottenberg, A.M. (2013) Guidelines on the Consumption of Fats and Cardiovascular Health. Arquivos Brasileiros de Cardiologia, 100, 1-40.

[28] Sposito, A.C., Caramelli, B., Fonseca, F.A.H., Bertolami, M.C., Afiune Neto, A., Souza, A.D., et al. (2007) IV Brazilian Guideline of Dyslipidemia and Prevention of Atherosclerosis: Department of Atherosclerosis of the Brazilian Society of Cardiology. Arquivos Brasileiros de Cardiologia, 88, 2-19.

http://dx.doi.org/10.1590/S0066-782X2007000700002

[29] Estruch, R., Ros, E., Salas-Salvadó, J., Covas, M.I., Corella, D., Arós, F., et al. (2013) Primary Prevention of Cardiovascular Disease with Mediterranean Diet. The New England Journal of Medicine, 368, 1279-1290. http://dx.doi.org/10.1056/NEJMoa1200303

[30] Salgado, J.M., Bin, C., Mansi, D.N. and Souza, A. (2008) Effects of Avocado (Persea americana Mill) Variety Hass in Blood Lipids of Hypercholesterolemic Rats. Ciência e Tecnologia dos Alimentos, 28, 922-928. http://dx.doi.org/10.1590/S0101-20612008000400025

[31] Grant, W.C. (1960) Influence of Avocados on Serum Cholesterol. Proceedings of the Society for Experimental Biology and Medicine, 104, 45-47. http://dx.doi.org/10.3181/00379727-104-25722

[32] Carranza, J., Alvizouri, M., Alvarado, M.R., Chávez, F., Gómez, M. and Herrera, J.E. (1995) Effects of Avocado on the Level of Blood Lipids in Patients with Phenotype II and IV Dyslipidemias. Archivos del Instituto de Cardiología de мéxico, 65, 342-348. 
[33] Pérez Méndez, O. and García Hernández, L. (2007) High-Density Lipoproteins (HDL) Size and Composition Are Modified in the Rat by a Diet Supplemented with "Hass" Avocado (Persea americana Miller). Archivos del Instituto de Cardiología de México, 77, 17-24.

[34] Boshtam, M., Razavi, A.E., Pourfarzam, M., Ani, M., Naderi, G.A., Basati, G., et al. (2013) Serum Paraoxonase Activity Is Associated with Fatty Acid Composition of High Density Lipoprotein. Diseases Markers, 35, 273-280. http://dx.doi.org/10.1155/2013/612035

[35] Wang, L., Bordi, P.L., Fleming, J.A., Hill, A.M. and Kris-Etherton, P.M. (2015) Effect of a Moderate Fat Diet with and without Avocados on Lipoprotein Particle Number, Size and Subclasses in Overweight and Obese Adults: Randomized, Controlled Trial. Journal of the American Heart Association, 4, e001355. http://dx.doi.org/10.1161/jaha.114.001355

[36] Bastien, M., Poirier, P., Leimeux, I. and Després, J.P. (2014) Overview of Epidemiology and Contribution of Obesity to Cardiovascular Disease. Progress in Cardiovascular Disease, 56, 369-381. http://dx.doi.org/10.1016/j.pcad.2013.10.016

[37] Schwingshackl, L. and Hoffmann, G. (2012) Monounsaturated Fatty Acids and Risk of Cardiovascular Disease: Synopsis of the Evidence Available from Systematic Reviews and Meta-Analyses. Nutrients, 4, 1989-2007. http://dx.doi.org/10.3390/nu4121989

[38] Pieterse, E., Jerling, J.C., Oosthuizen, W., Kruger, H.S., Hanekom, S.M., Smuts, C.M., et al. (2005) Substitution of High Monounsaturated Fatty Acid Avocado for Mixed Dietary Fats during an Energy-Restricted Diet: Effects on Weight Loss, Serum Lipids, Fibrinogen, and Vascular Function. Nutrition, 21, 67-75. http://dx.doi.org/10.1016/j.nut.2004.09.010

[39] Sloth, B., Due, A., Larsen, T.M., Holst, J.J., Heding, A. and Astrup, A. (2009) The Effect of a High-MUFA, LowGlycaemic Index Diet and a Low-Fat Diet on Appetite and Glucose Metabolism during a 6-Month Weight Maintenance Period. British Journal of Nutrition, 101, 1846-1858. http://dx.doi.org/10.1017/S0007114508137710

[40] Champagne, C.M., Broyles, S.T., Moran, L.D., Cash, K.C., Levy, E.J., Lin, P.-H., et al. (2011) Dietary Intakes Associated with Successful Weight Loss and Maintenance during the Weight Loss Maintenance Trial. Journal of the American Dietetic Association, 111, 1826-1835. http://dx.doi.org/10.1016/j.jada.2011.09.014

[41] Schmidt, M.S., Duncan, B.B., Azevedo e Silva, G., Menezes, A.M., Monteiro, C.A., Barreto, S.M., et al. (2011) Chronic Non-Communicable Diseases in Brazil: Burden and Current Challenges. Lancet, 377, 1949-1961. http://dx.doi.org/10.1016/S0140-6736(11)60135-9

[42] Mancia, G., Fagard, R., Narkiewicz, K., Redon, J., Zanchetti, A., Bohm, M., et al. (2013) ESH/ESC Guidelines for the Management of Arterial Hypertension: The Task Force for the Management of Arterial Hypertension of the European Society of Hypertension (ESH) and of the European Society of Cardiology (ESC). European Heart Journal, 34, 2159-2219. http://dx.doi.org/10.1093/eurheartj/eht151

[43] Schwingshackl, L., Strasser, B. and Hoffmann, G. (2011) Effects of Monounsaturated Fatty Acids on Cardiovascular Risk Factors: A Systematic Review and Meta-Analysis. Annals of Nutrition and Metabolism, 59, 176-186. http://dx.doi.org/10.1159/000334071

[44] Ojewole, J.A., Kamadyaapa, D.R., Gondwe, M.M., Moodley, K. and Musabayane, C.T. (2007) Cardiovascular Effects of Persea americana Mill (Lauraceae) (Avocado) Aqueous Leaf Extract in Experimental Animals. Cardiovascular Journal of Africa, 18, 69-76.

[45] Adeboye, J.O., Fajonyomi, M.O., Makinde, J.M. and Taiwo, O.B. (1999) A Preliminary Study on the Hypotensive Activity of Persea americana Leaf Extracts in Anaesthetized, Normotensive Rats. Fitoterapia, 70, 15-20. http://dx.doi.org/10.1016/S0367-326X(98)00015-X

[46] Owolabi, M.A., Jaja, S.I. and Coker, H.A.B. (2005) Vasorelaxant Action of Aqueous Extract of the Leaves of Persea americana on Isolated Thoracic Rat Aorta. Fitoterapia, 76, 567-573. http://dx.doi.org/10.1016/j.fitote.2005.04.020

[47] Imafidon, K.E. and Amaechina, F.C. (2010) Effects of Aqueous Seed Extract of Persea americana Mill. (Avocado) on Blood Pressure and Lipid Profile in Hypertensive Rats. Advances in Biological Research, 4, 116-121. 